Royal College of Physicians, Fractured neck of femur provention and munasement Report London: Roval College of Physicians, 1989.

2 Kanis JA, Passmore R. Calcium supplementation of the diet-II. Br Med 1989;298:205-8

3 Cooper C, Barker DJP, Wickham C. Physical activity, muscle strength, an calcium intake in fracture of the proximal femur in Britain. Br. Med 1988;297:14+3-6

4 Holbrook TL, Barrett-Connor E, Wingard DL. Dictary calcium and risk of hip fracture: $1+$ vear prospective population study. Lancet 1988;ii: 1046-9.

Breslow NE, Day NE. Conditional logistic regression for matched sets. In Breslow NE, Day NE, eds. Statistical methods in cancer research. Vol 1. The analvsis of case comtrol studies. Lvons: International Agency for Research on Cancer, 1980:248-79.

6 Evans JG, Prudham D, Wandless I. A prospective studv of fractured proximal femur: incidence and outcome. Public Health 1979;93:235-41

Baker MR. An incestigation into secular trends in the incidence of femoral neck fracture using Hospital Activity Analysis. Public Health 1980;94:368$7+$.
8 Marr JW. Individual dietary surveys: purposes and methods, World Rev Nutr Diet 1971:13:105-64.

9 Lau E.MC, Donnan S, Barker DJP, Cooper C. Physical activity and calcium intake in fracture of the proximal femur in Hong Kong. Br Med $\mathrm{f}$ 1988:297:1+41-3

10 Boyce W J, Vessey MP. Habitual physical inertia and other factors in relation to fracture of proximal femur. Age Ageing 1988;17:319-27.

11 Smith R. Exercise and osteoporosis. Br.Med 7 1985;290:1163-4.

2 Huddleston AL, Rockwell D, Kulund DN, Harrison B. Bone mass in lifetime tennis athletes. FAMA 1980;244:1107-9.

13 Chow R, Harrison JE, Notarius CE. Effect of two randomised exercise programmes on bone mass of healthy postmenopausal women. $\mathrm{Br} \mathrm{Med} \mathcal{f}$ 1987;295:1+41-4.

14 Wickham C, Cooper C, Margetts BM, Barker DJP. Muscle strength, activity, housing and the risk of falls in elderly people. Age Ageing 1989;18:47-51

Accepted 1 A ugust 1989

\title{
Improved prognosis since 1969 of myocardial infarction treated in a coronary care unit: lack of relation with changes in severity
}

\author{
John L Hopper, Bhupendra Pathik, David Hunt, William W C Chan
}

Abstract

Objective-To study changes from 1969 to 1983 in the prognosis of patients with acute myocardial infarction treated in a coronary care unit.

Design-Mortality follow up of all patients with definite acute myocardial infarction.

Setting-The coronary care unit of the Royal Melbourne Hospital, a tertiary referral centre.

Subjects - 4253 Patients (3366 men, 887 women) admitted from 1969 to 1983.

Main outcome measure-Mortality recorded at discharge from hospital and 12 months after admission.

Results-Details of clinical findings, history, electrocardiograms, arrhythmias, and radiological findings were recorded on admission. Mean ages were $\mathbf{6 3}$ for women and 57 for men, and women had haemodynamically more severe infarcts than men. In the later years patients were older and had less severe infarcts. Overall, hospital mortality in men was $16.7 \%$ in $1969-73$ and $8.5 \%$ in $1979-83$ and declined in all grades of the Norris and Killip infarct severity indices compared with a constant $19.2 \%$ in women. Even after adjustment for age and severity by logistic regression, hospital mortality fell in men by an average of $8 \%(95 \%$ confidence interval $4 \%$ to $11 \%)$ a year but remained constant in women. By 1983 male mortality was $60 \%$ that of women of similar age and comparable severity of infarction. Mortality of hospital survivors at 12 months declined by $7 \%(4 \%$ to $9 \%)$ a year in both sexes, even after adjustment for age and severity, with a male to female mortality ratio of about $0 \cdot 8$. New indices were derived to predict mortality in hospital and at 12 months.

Conclusion-The observed declines in mortality cannot be explained by changes in severity of infarction or in prognostic characteristics of patients.

Royal Melbourne Hospital, Department of Cardiology, Melbourne, Victoria 3050, Australia

Bhupendra Pathik, FRACP

visiting associate

David Hunt, FRACP,

director

William W C Chan, FRACP, cardiologist

Correspondence to: Dr Hunt.

Br.Med f 1989;299:892-6 however, that patients with acute myocardial infarction the at home had better survival than those ad to hospital. ${ }^{1314}$ Reservations have been expressed about the effectiveness of coronary care units, ${ }^{15}$ and some have suggested that the decline in mortality from acute myocardial infarction in the United States may have been due to a higher proportion of "milder" cases among patients admitted to these units. ${ }^{16} 17$

This study was undertaken to ascertain whether the prognosis of patients with acute myocardial infarction admitted to the coronary care unit at the Royal Melbourne Hospital had changed between 1969 and 1983 and, if so, whether this change could be explained by any changes in the age distribution of patients admitted or in the severity of their infarctions. A previous report from this unit showed a significant fall in mortality in patients with $\mathrm{Q}$ wave myocardial infarction in mild and severe categories between 1969 70 and 1974-75 but no change among patients with cardiogenic shock. ${ }^{18}$

\section{Methods}

The Royal Melbourne Hospital is a 620 bed tertiary referral hospital affiliated to the university. Patients with suspected or definite acute myocardial infarction are admitted to the coronary care unit irrespective of age, provided beds are available. The general function and policies of the unit have been reported. ${ }^{19}$ From 1969 patient data were recorded by medical staff on questionnaire forms. This study was confined to patients with definite acute myocardial infarction. ${ }^{2021}$ Characteristics recorded for each patient on admission included history; clinical, electrocardiographic, and radiological findings; and arrhythmias. Outcome was recorded later.

Patients were classified by severity according to the Killip classification': class I-no heart failure; class II - heart failure (appearance of third heart sound or presence of basal crepitations or pulmonary congestion on radiograph, or both); class III - severe heart failure (pulmonary oedema); and class IV - cardiogenic shock. The Norris index of severity was computed from age, heart size, radiological changes in lung fields, location of infarct, systolic blood pressure, and history of ischaemia. ${ }^{+}$

From 1969 to 1983,8135 patients were admitted to the coronary care unit, of whom $4340(53 \%)$ had definite acute myocardial infarction. For 4253 of these patients ( 3366 men, 887 women) we had data on mortality at discharge from hospital and at 12 months after admission, and they constitute the present study population.

\section{STATISTICAL METHODS}

A tendency for the mortality to change over the 


\begin{tabular}{|c|c|c|c|c|c|c|c|c|c|c|c|c|}
\hline \multirow[b]{2}{*}{ Age } & \multicolumn{3}{|c|}{$1969-73$} & \multicolumn{3}{|c|}{$1974-8$} & \multicolumn{3}{|c|}{$1979-83$} & \multicolumn{3}{|c|}{ Total } \\
\hline & No $(\%)$ & $\begin{array}{c}\text { Hospital } \\
\text { mortality } \\
(\%)\end{array}$ & $\begin{array}{l}12 \text { Month } \\
\text { mortality } \\
(\%)\end{array}$ & No $(\%)$ & $\begin{array}{c}\text { Hospital } \\
\text { mortality } \\
(\%)\end{array}$ & $\begin{array}{l}12 \text { Month } \\
\text { mortality } \\
(\%)\end{array}$ & No $(\%)$ & $\begin{array}{c}\text { Hospital } \\
\text { mortality } \\
(\%)\end{array}$ & $\begin{array}{l}12 \text { Month } \\
\text { mortality } \\
(\%)\end{array}$ & No (\%) & $\begin{array}{c}\text { Hospital } \\
\text { mortality } \\
(\%)\end{array}$ & $\begin{array}{l}12 \text { Month } \\
\text { mortality } \\
(\%)\end{array}$ \\
\hline \multicolumn{13}{|c|}{ Men } \\
\hline$<40$ & $45 \quad(5)$ & $2 \cdot 2$ & $4 \cdot 5$ & $57 \quad(5)$ & $3 \cdot 5$ & $10 \cdot 9$ & $59 \quad(5)$ & $1 \cdot 7$ & 6.9 & 161 & $2 \cdot 5$ & $7 \cdot 6$ \\
\hline $40-49$ & $189(21)$ & $12 \cdot 2$ & $6 \cdot 6$ & $219(17)$ & $4 \cdot 6$ & $6 \cdot 8$ & $154(13)$ & $2 \cdot 6$ & $3 \cdot 3$ & $562(17)$ & $6 \cdot 6$ & $7 \cdot 6$ \\
\hline $50-59$ & 347 (39) & $12 \cdot 7$ & $12 \cdot 9$ & $438(35)$ & $13 \cdot 0$ & 8.9 & $440(36)$ & $5 \cdot 9$ & $8 \cdot 7$ & $1225(36)$ & $10 \cdot 4$ & 9.9 \\
\hline $60-69$ & $260(29)$ & $23 \cdot 8$ & $23 \cdot 2$ & $430(34)$ & $14 \cdot 4$ & $16 \cdot 6$ & $412(34)$ & $10 \cdot 7$ & $7 \cdot 9$ & $1102(33)$ & $15 \cdot 3$ & $14 \cdot 6$ \\
\hline$\geqslant 70$ & $52(6)$ & $38 \cdot 5$ & $31 \cdot 3$ & $113(9)$ & $24 \cdot 8$ & $20 \cdot 0$ & $151(12)$ & $19 \cdot 2$ & 13.9 & $316(9)$ & $24 \cdot 1$ & $18 \cdot 4$ \\
\hline Total & 893 & $16 \cdot 7$ & $15 \cdot 6$ & 1257 & $12 \cdot 7$ & $12 \cdot 2$ & 1216 & $8 \cdot 5$ & $8 \cdot 2$ & 3366 & $12 \cdot 2$ & $11 \cdot 6$ \\
\hline \multicolumn{13}{|c|}{ Women } \\
\hline$<40$ & $6(3)$ & & $16 \cdot 7$ & $5(2)$ & & $20 \cdot 0$ & $10(3)$ & & & $21 \quad(3)$ & & $9 \cdot 5$ \\
\hline $40-49$ & $18(9)$ & & $16 \cdot 7$ & $32(10)$ & $13 \cdot 4$ & & $15(4)$ & $6 \cdot 7$ & $7 \cdot 1$ & $65(7)$ & $6 \cdot 2$ & $6 \cdot 6$ \\
\hline $50-59$ & $73(37)$ & $20 \cdot 6$ & $17 \cdot 2$ & $82(25)$ & $13 \cdot 4$ & $7 \cdot 6$ & $71(19)$ & $4 \cdot 2$ & 8.9 & $226(26)$ & $12 \cdot 8$ & $11 \cdot 2$ \\
\hline $60-69$ & $61(31)$ & $16 \cdot 4$ & $25 \cdot 5$ & $153(47)$ & $23 \cdot 5$ & $18 \cdot 8$ & $152(42)$ & $17 \cdot 1$ & $13 \cdot 5$ & $366(41)$ & $19 \cdot 7$ & $17 \cdot 7$ \\
\hline$\geqslant 70$ & $39(20)$ & $38 \cdot 5$ & $29 \cdot 2$ & $52(16)$ & $28 \cdot 8$ & $18 \cdot 9$ & $118(32)$ & $30 \cdot 5$ & $12 \cdot 2$ & $209(24)$ & $31 \cdot 6$ & $16 \cdot 8$ \\
\hline Total & 197 & $20 \cdot 3$ & $21 \cdot 7$ & 324 & $19 \cdot 7$ & $13 \cdot 8$ & 366 & $18 \cdot 3$ & $11 \cdot 4$ & 887 & $19 \cdot 2$ & $14 \cdot 5$ \\
\hline
\end{tabular}

study period was first assessed by examining crude and age-sex specific mortalities. The influence of each admission characteristic on prognosis was studied.

For each sex, multivariate logistic regression analyses ${ }^{22}$ of mortality were performed using the generalised linear interactive modelling package (GLIM), ${ }^{2.3}$ adjusting for age, severity, and year of admission. Severity was represented in two ways, firstly, by using clinical characteristics shown in these data to be independent prognostic factors, and, secondly, by using the established Killip classification and Norris index. A significant effect of year of admission would indicate that an observed trend could not be explained, using these statistical methods, by changes in age or severity of infarctions.

Let $p$ be the probability a patient does not survive a given period. Let $\mathrm{x}_{1}, \ldots, \mathrm{x}_{\mathrm{n}}$ represent explanatory variables such as age, sex, an admission characteristic, or year(s) of admission. The model asssumes that the expected value, $\mathrm{E}$, of the logarithm of the odds, the logit, is a linear function of these variables - that is,

$\mathrm{E}[\operatorname{logit}(\mathrm{p})]=\mathrm{E}[\log (\mathrm{p} /(1-\mathrm{p}))]=\mathrm{b}_{0}+\mathrm{b}_{1} \mathrm{x}_{1}+\mathrm{b}_{2} \mathrm{x}_{2} \ldots+\mathrm{b}_{\mathrm{n}} \mathrm{x}_{\mathrm{n}} \cdot(1)$ The coefficients $b_{0}, \ldots, b_{n}$ represent the "effects" of the variables and are estimated by maximum likelihood. Modelled associations with age and clinical characteristics form the bases of the new Royal Melbourne Hospital indices of severity that we derived from these data.

If $p_{j}$ is the probability of dying if $x_{i}=i, j=0$ or 1 , and if $x_{i}=1$ if the factor is present, else 0 , then

$$
\mathrm{e}^{\mathrm{h}_{\mathrm{i}}}=\mathrm{p}_{1}\left(1-\mathrm{p}_{0}\right) /\left(1-\mathrm{p}_{1}\right) \mathrm{p}_{0} \text {. }
$$

If $p_{0}$ is small the mortality when factor $i$ is present is approximately $\mathrm{e}^{\mathrm{b}_{1}}$ times greater than in the absence of the factor. The baseline coefficient $b_{0}$ corresponds to an individual with 0 on all variables. For the continuous variate year of admission $b_{i}$ estimates an average change over the study period, which when $p$ is close to 0.5 is about one quarter of the linear change in p per year, while if $\mathrm{p}$ is small it is approximately the percentage change in $p$ per year. A negative estimate means that $p$ is less in the later years.

Changes in mean age and in mean Norris index were analysed by linear regression. Throughout means and parameter estimates are presented with their standard errors in parentheses.

\section{Results}

From 1969-73 to $1979-83$ the median delay from onset of symptoms to admission to the coronary care unit decreased from 5.5 to 3.8 hours. The proportion of delays between onset of symptoms and admission to the emergency department of more than 24 hours fell from $15 \%(167 / 1090)$ to $8 \%(123 / 1582)$. From the emergency department to the coronary care unit the proportion of delays of less than one hour fell from $43 \%$ $(474 / 1090)$ to $22 \%(349 / 1582)$ and the proportion of delays of more than four hours from $24 \%(261 / 1090)$ to $11 \%(167 / 1582)$.

\section{ANALYSIS OF ADMISSION CHARACTERISTICS AND SEVERITY} OF INFARCT

A logistic regression analysis of the characteristics recorded on admission ${ }^{24}$ showed that almost all characteristics were less common in the later years, irrespective of adjustments for age and sex. Characteristics were more common in older patients. Men were more likely to have had a previous acute myocardial infarction, a $Q$ wave infarct, atrial arrhythmias, ventricular premature beats, and ventricular tachycardia. Women were more likely to have had hypertension, diabetes, cardiogenic shock, ventricular standstill, and third degree atrioventricular block and to have never smoked.

The mean Norris index was lower in men $(5 \cdot 72$ $(0.05))$ than in women $(6.44(0 \cdot 12))$ and increased with age. In later years patients had on average less severe infarcts. After adjusting for age the mean index fell with year of admission by $0.12(0.01)$ a year, independent of sex, and was on average $0.25(0.12)$ lower in men. The proportion of admissions without failure or shock (Killip class I) averaged $0 \cdot 49$ (men 0.50 , women $0 \cdot 46$ ). By multiple logistic regression, after adjustment for an increase with age that was independent of sex, this proportion increased with year of admission by about $0.015(0.002)$ a year.

\section{ANALYSIS OF MORTALITY BY AGE, SEX, AND YEAR OF} ADMISSION

Mortality in hospital and mortality after 12 months in those who survived to leave hospital are shown by sex, age, and year of admission in table I. Men comprised $79 \%(3366 / 4253)$ of those admissions throughout. The proportions of patients in the older age groups increased with admission period. The mean age ( $57 \cdot 1$ men, $63 \cdot 2$ women) increased by $0 \cdot 3$ years per year. Both mortalities tended to decrease across the admission periods, especially in the older age groups. Univariate logistic regression analyses showed that both mortalities increased with age and were higher in women. For men mortality in hospital declined with year of admission, while for women it was constant. The 12 month mortality of survivors fell with year of admission in both sexes at a similar rate. 
ANALYSIS OF MORTALITY BY ADMISSION

CHARACTERISTICS

The odds ratios given by equation 2 and presented in table II show that for all characteristics except hypertension the presence of that characteristic was associated with a significantly increased hospital mortality, independent of sex and adjustment for age and year of admission. A similar conclusion applied to the 12 month mortality of hospital survivors, except that some characteristics were not significant risk factors for one or both sexes. The odds ratios for most of the major risk factors decreased with age.

Major risk factors for hospital mortality were cardiogenic shock and ventricular standstill, each associated with over $80 \%$ mortality (298/356 and $259 / 317$ respectively). Other high risk factors were third degree atrioventricular and bundle branch blocks, ventricular fibrillation, and tachycardia. Major risk factors for 12 month mortality of survivors were bundle branch block, pulmonary oedema, enlarged heart, and a history of previous acute myocardial infarction.

\section{ANALYSIS OF MORTALITY BY AGE, SEX, PROGNOSTIC} VARIABLES, AND YEAR OF ADMISSION

Tables III and IV present the results of logistic regression analyses of hospital mortality and 12 month mortality respectively, listing the logistic regression coefficients $\left(b_{0}, b_{1}, \ldots, b_{n}\right.$ of equation 1$)$ and their standard errors for age, sex, and the characteristics found to be independently predictive of mortality. None of the coefficients for these independent factors showed variation with age or sex.

For hospital mortality nine independent prognostic factors were identified. After adjustment for these there was a decline in mortality with year of admission $(p<0.001)$ for men, corresponding to an average fall of about $8 \%$ a year. For women the trend was not significant, and it was different from that for men $(p<0.05)$. When we compared men and women of the same age and prognostic profile the model predicted that in 1969 women had about $70 \%$ of the mortality of men, whereas by 1983 the relation had reversed and men had about $60 \%$ of the mortality of women.

For 12 month mortality there were eight independent prognostic factors. After adjusting for these the decline in mortality with year of admission $(p<0.001$ men; $\mathrm{p}<0.05$ women) was independent of sex and equal to an average fall of about $7 \%$ per year. Men had average mortality about $80 \%$ of that of women of similar age and prognostic profile $(\mathrm{p}=0 \cdot 06$, two sided $)$.
TABLE III-Hospital mortality logistic regression coefficients and standard errors for independent prognostic factors, age, sex, and year of admission. Coefficients were used to construct the Royal Melbourne Hospital index for hospital mortality following equation 3

\begin{tabular}{|c|c|c|}
\hline \multirow[b]{2}{*}{ Characteristic } & \multicolumn{2}{|c|}{ Hospital mortality } \\
\hline & $\begin{array}{l}\text { RMH index } \\
\text { coefficient }\end{array}$ & Standard error \\
\hline Baseline & $-7 \cdot 027$ & $0 \cdot 600$ \\
\hline Cardiogenic shock & 3.060 & $0 \cdot 182$ \\
\hline Ventricular standstill & 2.656 & $0 \cdot 196$ \\
\hline Third degree atrioventricular block & 0.090 & $0 \cdot 181$ \\
\hline Ventricular fibrillation & 0.893 & $0 \cdot 167$ \\
\hline Angina & 0.714 & $0 \cdot 134$ \\
\hline Pulmonary oedema & 0.625 & $0 \cdot 160$ \\
\hline Never smoked & 0.556 & $0 \cdot 142$ \\
\hline Bundle branch block & 0.607 & $0 \cdot 153$ \\
\hline Anterior infarct & $0 \cdot 507$ & $0 \cdot 133$ \\
\hline Age (years) & 0.0477 & 0.0076 \\
\hline $\operatorname{Sex}(1$ if $\operatorname{man}, 0$ if woman & 0.662 & $0 \cdot 312$ \\
\hline Year of admission from 1969 (men) & -0.0765 & 0.0186 \\
\hline Year of admission from 1969 (women) & 0.0036 & 0.0300 \\
\hline
\end{tabular}

TABLE IV-12 Month mortality of hospital survivors. Logistic regression coefficients and standard errors for independent prognostic factors, age, sex, and year of admission. Coefficients were used to construct the Royal Melbourne Hospital index for 12 month mortality of hospital survivors following equation 3

\begin{tabular}{|c|c|c|}
\hline \multirow[b]{2}{*}{ Characteristic } & \multicolumn{2}{|c|}{12 Month mortality } \\
\hline & $\begin{array}{l}\text { RMH index } \\
\text { coefficient }\end{array}$ & Standard error \\
\hline Baseline & -3.638 & $0 \cdot 450$ \\
\hline Bundle branch block & $0 \cdot 816$ & $0 \cdot 139$ \\
\hline Enlarged heart & 0.554 & $0 \cdot 112$ \\
\hline Previous acute myocardial infarction & $0 \cdot 515$ & $0 \cdot 115$ \\
\hline Atrial arrhythmias & 0.326 & $0 \cdot 131$ \\
\hline Pulmonary oedema & $0 \cdot 497$ & $0 \cdot 146$ \\
\hline Sinus tachycardia & $0 \cdot 402$ & $0 \cdot 110$ \\
\hline Ventricular premature beats & $0 \cdot 235$ & $0 \cdot 109$ \\
\hline Angina & $0 \cdot 340$ & $0 \cdot 114$ \\
\hline Age (years) & 0.0210 & 0.0062 \\
\hline Sex ( 1 if man, 0 if woman) & $-0 \cdot 250$ & $0 \cdot 130$ \\
\hline Year of admission from 1969 & $-0.0673^{\star}$ & 0.0136 \\
\hline
\end{tabular}

* $-0.0633(\mathrm{SD} 0.0154)$ for men, $-0.0808(0.0275)$ for women.

There was no evidence that the rates of decline in mortality with year of admission depended on age or that there were any significant interactions between these trends and the prognostic factors, with one exception. For hospital mortality, once age and the other prognostic factors were in the model, the coefficient for ventricular fibrillation was $b=1.52-$ $0.012 \times($ year -1969$)$, suggesting that by 1983 there was no independent increased risk associated with ven-

TABLE II - Hospital mortality and 12 month mortality for men and women by characteristic and mortality odds ratio for the characteristic (equation 2) and its $95 \%$ confidence interval, after adjustment for age, sex, and year of admission by sex

\begin{tabular}{|c|c|c|c|c|c|c|c|c|}
\hline \multirow[b]{2}{*}{ Characteristic } & \multicolumn{4}{|c|}{ Hospital mortality } & \multicolumn{4}{|c|}{12 Months mortality } \\
\hline & Men & Women & $\begin{array}{c}\text { Characteristic } \\
\text { odds ratio }\end{array}$ & $\begin{array}{c}95 \% \\
\mathrm{CI}\end{array}$ & Men & Women & $\begin{array}{c}\text { Characteristic } \\
\text { odds ratio }\end{array}$ & $\begin{array}{c}95 \% \\
\mathrm{CI}\end{array}$ \\
\hline Previous acute myocardial infarction & $18 \cdot 4$ & $28 \cdot 3$ & 1.96 & $1 \cdot 62 \cdot 2 \cdot 36$ & $18 \cdot 1$ & $22 \cdot 7$ & $2 \cdot 10$ & $1 \cdot 70-2 \cdot 58$ \\
\hline Angina & $16 \cdot 9$ & $23 \cdot 6$ & 1.89 & $1 \cdot 57 \cdot 2 \cdot 27$ & $15 \cdot 4$ & $18 \cdot 7$ & $1 \cdot 80$ & $1 \cdot 46-2 \cdot 21$ \\
\hline Hypertension & $11 \cdot 7$ & $17 \cdot 5$ & $1 \cdot 13$ & $0.93 \cdot 1 \cdot 37$ & $12 \cdot 2$ & $15 \cdot 1$ & $1 \cdot 12$ & $0 \cdot 90-1 \cdot 38$ \\
\hline Diabetes & $17 \cdot 7$ & $29 \cdot 1$ & 1.57 & $1 \cdot 19 \cdot 2 \cdot 07$ & $14 \cdot 7$ & $27 \cdot 0$ & $1 \cdot 70^{\star}$ & $1 \cdot 24-2 \cdot 32$ \\
\hline Never smoked & $19 \cdot 5$ & $23 \cdot 8$ & 1.67 & $1 \cdot 37 \cdot 2 \cdot 04$ & $11 \cdot 0$ & $18 \cdot 4$ & $1 \cdot 02$ & $0 \cdot 80-1 \cdot 30$ \\
\hline Crepitations & $18 \cdot 7$ & $27 \cdot 1$ & $2 \cdot 82$ & $2 \cdot 31-3 \cdot 45$ & $16 \cdot 0$ & $16 \cdot 1$ & 1.69 & $1 \cdot 37-2 \cdot 08$ \\
\hline Cardiogenic shock & $80 \cdot 8$ & $81 \cdot 2$ & $54 \cdot 0$ & $39 \cdot 8 \cdot-73 \cdot 3$ & 21.9 & $22 \cdot 7$ & $1.93 t$ & $1 \cdot 0) 7-3.51$ \\
\hline Enlarged heart & $17 \cdot 1$ & $26 \cdot 5$ & 1.60 & $1.33-1.92$ & 18.9 & $21 \cdot 6$ & $2 \cdot 26$ & $1.8+-2.79$ \\
\hline Pulmonary venous congestion & $15 \cdot 3$ & $25 \cdot 8$ & 1.53 & $1.27 \cdot 1.83$ & $16 \cdot 7$ & $19 \cdot 8$ & $2 \cdot 13$ & $1 \cdot 73-2 \cdot 63$ \\
\hline Pulmonary oedema & $31 \cdot 0$ & $42 \cdot 1$ & $3 \cdot 64$ & $2 \cdot 95-4 \cdot 50$ & $24 \cdot 7$ & $27 \cdot 3$ & $2 \cdot 52$ & $1.93-3.29$ \\
\hline Anterior $(v$ inferior $)$ & $16 \cdot 1$ & $24 \cdot 4$ & 1.72 & $1 \cdot 44 \cdot 2 \cdot 07$ & 13.4 & $15 \cdot 6$ & $1 \cdot 25$ & $1 \cdot 02 \cdot 1 \cdot 54$ \\
\hline $\mathrm{Q}$ wave ( $v$ non-Q $\mathrm{Q}$ ave $)$ & $13 \cdot 3$ & $25 \cdot 4$ & 1.42 & $1 \cdot 12 \cdot 1 \cdot 79$ & 11.9 & $15 \cdot 5$ & $1 \cdot 32$ & $1 \cdot 03-1 \cdot 67$ \\
\hline Sinus tachycardia & $17 \cdot 9$ & $26 \cdot 7$ & $2 \cdot 17$ & $1 \cdot 81 \cdot 2 \cdot 60$ & $16 \cdot 0$ & $19 \cdot 2$ & 1.80 & $1 \cdot 47-2 \cdot 21$ \\
\hline Atrial arrhythmias & $20 \cdot 5$ & $27 \cdot 1$ & 1.49 & $1 \cdot 20-1 \cdot 84$ & $15 \cdot 2$ & $17 \cdot 5$ & 1.60 & $1 \cdot 25-2 \cdot 04$ \\
\hline Ventricular premature beats & $14 \cdot 3$ & $21 \cdot 0$ & $1 \cdot 17$ & $0 \cdot 97 \cdot 1 \cdot 40$ & $15 \cdot 1$ & $17 \cdot 1$ & $1 \cdot 48$ & $1 \cdot 21-1 \cdot 67$ \\
\hline Ventricular tachycardia & $26 \cdot 5$ & $36 \cdot 4$ & $3 \cdot 27$ & $2 \cdot 67 \cdot 4 \cdot 00$ & $16 \cdot 9$ & $21 \cdot 9$ & 1.66 & $1 \cdot 28-2 \cdot 14$ \\
\hline Ventricular fibrillation & $38 \cdot 7$ & $42 \cdot 6$ & $5 \cdot 56 \neq$ & $4 \cdot 43-6 \cdot 98$ & $20 \cdot 6$ & $20 \cdot 4$ & 1.99 & $1 \cdot 4+2 \cdot 75$ \\
\hline Ventricular standstill & $81 \cdot 7$ & $81 \cdot 8$ & $48 \cdot 1$ & $35 \cdot 0-66 \cdot 1$ & $29 \cdot 1$ & $18 \cdot 8$ & 1.72 & $0.91-3.25$ \\
\hline Bundle branch block & $34 \cdot 0$ & $49 \cdot 2$ & 4.68 & $3 \cdot 80-5 \cdot 76$ & $26 \cdot 1$ & $35 \cdot 9$ & $2 \cdot 87$ & $2 \cdot 21-3 \cdot 73$ \\
\hline Third degree atrioventricular block & $44 \cdot 4$ & $47 \cdot 7$ & 5.97 & $4 \cdot 74-7 \cdot 50$ & $12 \cdot 4$ & $20 \cdot 6$ & $1 \cdot 04$ & $0.70-1 \cdot 54$ \\
\hline
\end{tabular}

*Odds ratio in women, 3.00 , was higher than in men, $1.35 ; \mathrm{p}<0.05$.

tOdds ratio decreased with

fOdds ratio decreased with year of admission to about $6 \%$ ( $3 \%$ ) a vear. 
tricular fibrillation once the other factors had been considered $(\mathbf{p}<0 \cdot 01)$.

\section{ROYAL MELBOURNE HOSPITAL INDICES}

For a patient with any set of given characteristics the predicted probability of death at a given time point (the Royal Melbourne Hospital index) could be calculated from the coefficients in tables III or IV and equation 1 to be

RMH index $=e^{c} /\left(1+e^{c}\right)$, where $c=b_{0}+b_{1} x_{1}+\ldots+b_{n} x_{n}$. (3)

For example, a 53 year old non-smoking man with angina, admitted in 1979 with acute myocardial infarction and found to have an anterior infarct but no other complications would have a probability of dying in hospital of $\mathrm{e}^{\mathrm{c}} /\left(1+\mathrm{e}^{\mathrm{c}}\right)=0.056$, where $\mathrm{c}=-7 \cdot 027+$ $0 \cdot 714+0 \cdot 556+0 \cdot 507+0 \cdot 0477 \times 53+0 \cdot 662-0 \cdot 0765 \times$ (1979-1969).

The 320 patients who had an Royal Melbourne Hospital index for hospital mortality of $0 \cdot 10$ to $0 \cdot 25$ (of whom $80 \%$ (256) had a history of previous acute myocardial infarction and $82 \%$ (262) were aged over 60 , while none had cardiogenic shock or ventricular standstill) showed a significantly greater fall in mortality than did patients in other severity ranges based on the Royal Melbourne Hospital index. The observed mortality of this group was over $30 \%$ in 1969 73 , yet less than $10 \%$ in $1979-83$.

\section{ANALYSIS OF HOSPITAL MORTALITY BY THE NORRIS} INDEX AND KILLIP SCALE

Analysis of hospital mortality by the four Killip classes, age, and year of admission showed a decline of mortality with year of admission in men $(p<0.001)$ and to a lesser extent in women $(p<0 \cdot 05)$. Mortality increased with age in every class. In men in class IV mortality was above $80 \%$ (average $87 \%(136 / 156)$ ) from 1969 to 1979 but was successively $82 \%$ (18/22), $73 \%$ $(11 / 15), 67 \%(8 / 12), 64 \%(14 / 22)$, and $58 \%(7 / 12)$ in the

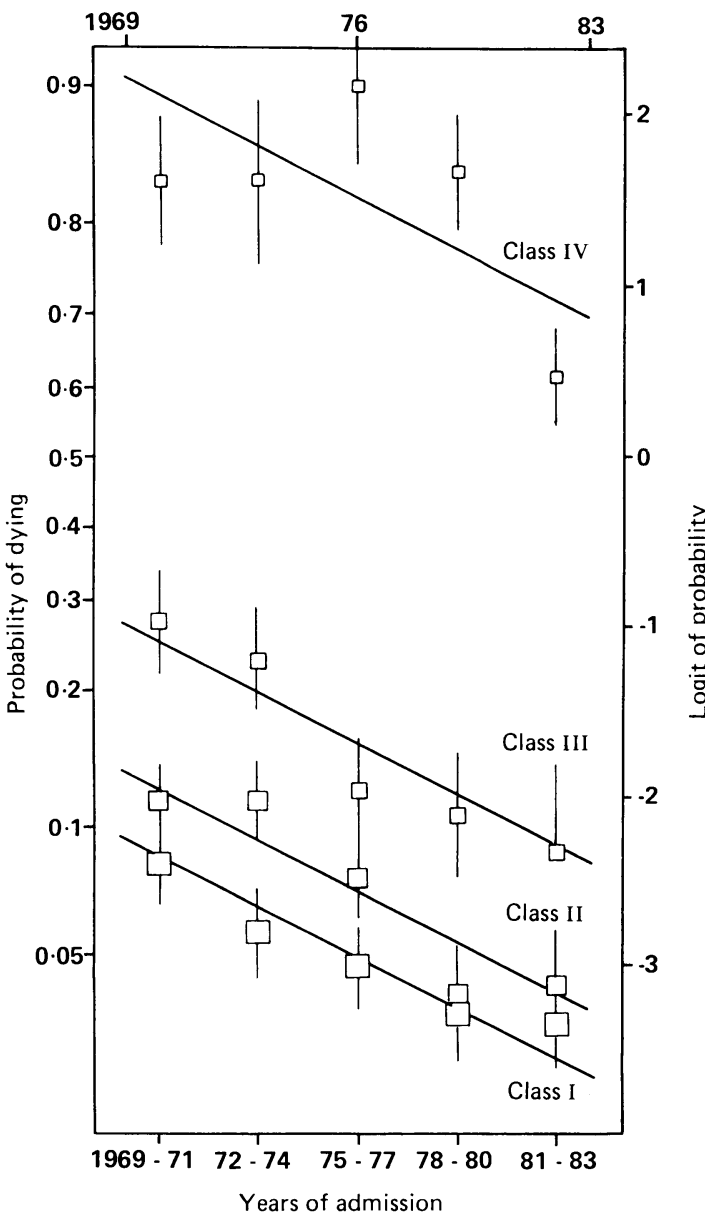

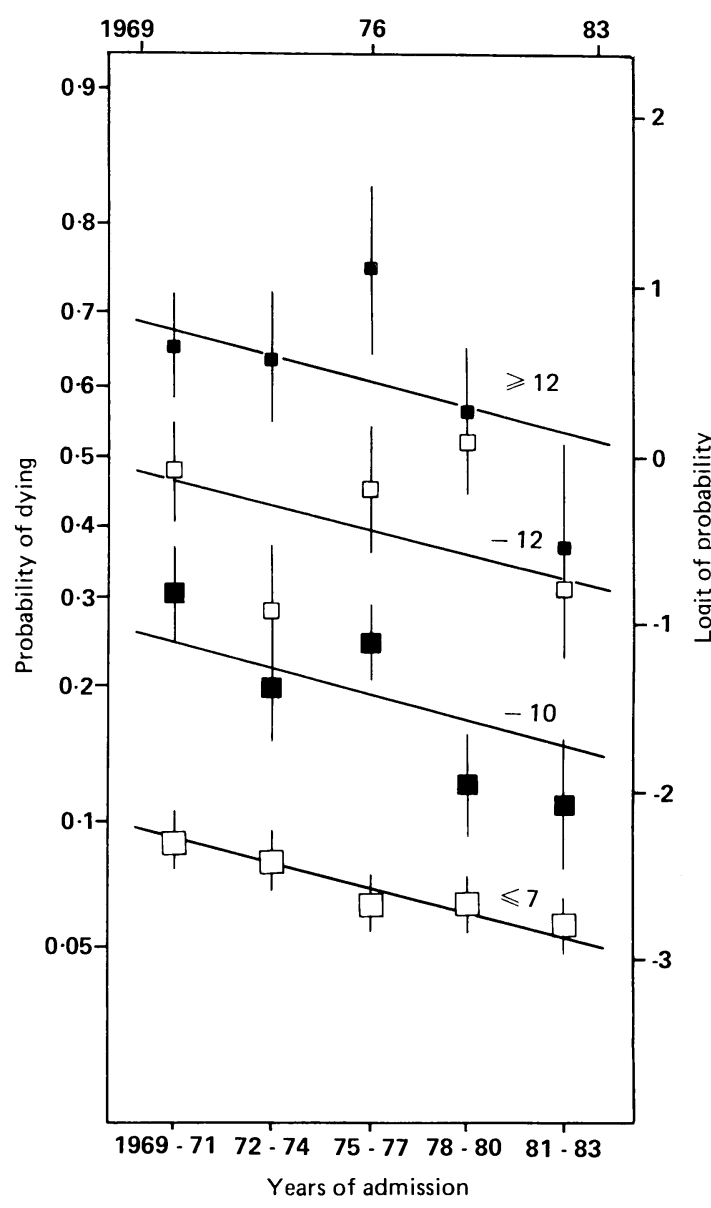

FIG 2-Hospital mortality for men for Norris index groupings by year of admission with best fitting linear logistic model (trend with year of admission $=-0.049 \pm 0.014$ ). Size of square suggestsnumber of patients in category; length of vertical line from point equals one standard error.

Norris index $\leqslant 7 \square ;-10 \square ;-12 \square ; \geqslant 12$ घ

next five years. In contrast, for women in class IV mortality averaged $77 \%(89 / 116)$ and was never less than $66 \%$ across the study period.

A similar analysis, using groupings of the Norris index instead, showed a decline with year of admission in men $(\mathrm{p}<0.001)$ but a non-significant decline in women. In men and in all age groups the most rapid decline with year of admission occurred in patients with a Norris index of 8 to 10 .

Figs 1 and 2 show hospital mortality for men by year of admission and by Killip class and Norris index groupings respectively. On the logistic scale the trends for mortalities to decrease with year of admission in each grouping were linear and parallel. As more recent patients were older, statistically these trends would be even greater in absolute terms if they were adjusted for age.

\section{Discussion}

From 1969 to 1983 the crude hospital mortality for men, the crude 12 month mortality of hospital survivors of both sexes, and the severity of acute myocardial infarction among patients of both sexes treated in the coronary care unit at the Royal Melbourne Hospital declined, while the average ages of the patients increased. Multivariate analyses, using as measures of severity either clinical characteristics (tables III and IV) or the Killip classification and Norris index (figs 1 and 2), showed that the falls in crude mortalities were greater than could be explained by the decline in the severity of acute myocardial infarction.

Improvement in hospital mortality among men occurred at all levels of age and severity. Mortality fell 
by about $8 \%$ a year in low risk men of similar age and severity. Hospital mortality among women remained constant. Improvement in 12 month mortality of hospital survivors was seen at all levels of age and severity in both men and women; this was equivalent to a reduction of about $7 \%$ a year, controlling for age and severity. Men showed an overall reduction in 12 month mortality of $15 \%$ a year.

Women were older than men and had more severe infarcts. Greater proportions of women had the severest prognostic factors of cardiogenic shock, ventricular standstill, and third degree atrioventricular block, and on average women had higher scores on the Norris index and Killip scale. Nevertheless, a higher overall mortality in women than in men, more so in the later years, was still evident after adjusting for these factors. Statistical modelling predicted that, although the hospital mortality of men was nearly twice that of women of similar age and clinical characteristics in 1969 , by 1983 it was less than two thirds. For 12 month mortality of hospital survivors the ratio of male to female mortality was constant at about $0 \cdot 8$. Therefore a higher mortality rate in women with acute myocardial infarction ${ }^{526}$ cannot be explained by sex differences in the age or in the severity measures considered in this study.

Two predictors of mortality, the Royal Melbourne Hospital indices, were derived using the measured patient characteristics shown to be independently predictive of mortality in this study. These indices might prove to be useful because they are derived from large samples and give direct estimates of mortality. They suggest that ventricular fibrillation has become a less important predictor of mortality in recent years.

Patients who had never smoked were over $50 \%$ more likely to die in hospital than patients who had ever smoked, taking account of their ages and their having had more severe infarcts, ${ }^{,-}$but the reasons for this are not clear.

There was a decrease of about $30 \%$ in the median time between onset of symptoms and admission to the coronary care unit over the study period, with at least a halving of long delays but no improvement in short delays. The decline in the severity of acute myocardial infarction over the study period was consistent, except that cardiogenic shock and ventricular tachycardia showed only a marginal decline in prevalence.

In recent years mortality from coronary heart disease has fallen in Australia, ${ }^{28} 29$ while that from acute ischaemic heart disease has fallen in the United States. ${ }^{30}$ If the epidemic of clinical coronary heart disease is waning then the residual cases would be expected to occur among older people and might be less severe, as we have observed. Our data are, however, hospital based, and there are other possible explanations such as confounding by variables other than age or sex, a tendency for younger patients with acute myocardial infarction to seek treatment outside public hospitals, or a change in admissions policy within the hospital. Nevertheless, the time trends we have found are consistent with a waning of the epidemic of clinical coronary heart disease in the community.

Our analyses have shown that, despite the fact that more recently admitted patients have included a higher proportion of people with milder infarctions, their better prognosis was greater than could be explained by the lower severity of their infarction. This was particularly true among men, who constituted $80 \%$ of patients with acute myocardial infarction.

This paper is dedicated to past and present nurses and doctors of the coronary care unit at the Royal Melbourne Hospital, and to Dr J Graeme Sloman, who started the unit in 1963 and its research data bank. We thank Dr J R E Fraser, Professor J D Mathews, and Mr J Campbell. This work was supported by the Australian National Health and Medical Research Council.

1 Killip T, Kimball JT. Treatment of myocardial infarction in a coronary care unit: a two year experience with 250 patients. Am $\mathcal{F}$ Cardiol 1967;20:457-64. 2 MacMillan RL, Brown KWG, Peckham GB. Changing perspectives in coronary care. A five year study. Am 7 Cardiol 1967;20:451.

3 Restieaux N, Bray C, Bullard $\mathrm{H}$, et al. 150 patients with cardiac infarction treated in a coronary care unit. Lancet $1967 ;$; :1285-9.

treated in a coronary care unit. Lancet 1967;i:1285-9.
4 Norris RM, Brandt PWT, Caughey DE, Lee AJ, Scott PJ. A new coronary Norris RM, Brandt PWT, Caughey DE,
prognostic index. Lancet 1969;i:274-8.

prognostic index. Lancet 1969;i:274-8.
5 Gillum RF, Folsom SR, Blackburn H. Decline in coronary heart disease mortality. Old questions and new facts. Am $\mathcal{J}$ Med 1984;76:1055-65.
mes.

6 Goldman L, Cook E. The decline in ischemic heart disease mortality rates. An analysis of the comparative effects of medical interventions and changes in lifestyle. Ann Intern Med 1984;101:825-36.

7 Marmot MG. Interpretations of trends in coronary heart disease mortality. Acta Med Scand [Suppl] 1985; 701:58-65.

8 Thompson PL, Vandongen YK, Eccles JL, de Klerk NH. Assessment of the impact of coronary artery surgery on mortality after recovery from myocardial infarction. Aust NZ F Med 1984;14:424-9.

9 Hofvendahl S. Influence of treatment in a coronary care unit on prognosis in acute myocardial infarction. Acta Med Scand 1971;519 (suppl): 1-78.

10 Christiansen I, Iversen K, Skouby AP. Benefits obtained by the introduction of a coronary care unit: a comparative study. Acta Med Scand 1971;189: 285-91.

11 Chapman BL. Effect of coronary care on myocardial infarct mortality. Br Heart f 1979;42:386-95.

12 Bain C, Siskind V, Neilson G. Site of care and survival after acute myocardial infarction. Med f A A ust 1981;ii: 185-8.

13 Mather HG, Morgan DC, Pearson NG, et al. Myocardial infarction: a comparison between home and hospital care for patients. Br Med $\mathcal{f}$ 1976;: :925-9.

14 Hill JD, Hampton JR, Mitchell JRA. A randomised trial of home-vs-hospital management for patients with suspected myocardial infarction. Lancet 1978;i:837-41.

15 Colling A, Dellipiani AW, Donaldson RJ, McCormack R. Teeside Coronary Survey: an epidemiological study of acute attacks of myocardial infarction. Br.Med J 1976;ii:1169-72.

16 Rose G. The contribution of intensive coronary care. British foumal of Preventive and Social Medicine 1975;29:147-50.

17 Stern MP. The recent decline in ischaemic heart disease mortality. Ann Intern Med 1979;91:630-40.

18 Hunt D, Sloman G, Christie D, Pennington C. Changing patterns and mortality of acute myocardial infarction in a coronary care unit. Br Med $\mathcal{J}$ 1977; i:795-8

19 Hamer A, Hunt D, Sloman JG. The coronary care unit: experience at the Royal Melbourne Hospital. Patient Management 1980;Sep:49-57.

20 World Health Organisation. Ischaemic heart disease registers: report of a working group. Copenhagen: World Health Organisation, 1968.

21 World Health Organisation Regional Office for Europe. Myocardial infarction community registers. Public Health in Europe 1977;5:1-232.

22 McCullagh P, Nelder JA. Generalized linear models. London: Chapman and Hall, 1983 .

23 Baker AJ, Nelder JA. The GLIM System. Release 3. Oxford: Numerical Algorithms Group, 1978.

24 Pathik B. Changing patterns and trends in acute myocardial infarction. [MD thesis.] Melbourne: University of Melbourne, 1986.

25 Puletti $M$, Senseri L, Curione M, Erba S, Borgia CL. Acute myocardial infarction. Sex related differences in prognosis. Am Heart $f$ 1984;108:63-6.

26 Peter T, Harper R'T, Luxton M, Penington C, Sloman JG. Acute myocardial infarction in women. The influence of age on complications and mortality.
intiol infarction in women. The

27 Kelly TL, Gilpin E, Ahnves S, Henning H, Ross J. Smoking status at the time of acute myocardial infarction and subsequent prognosis. Am Heart $\mathcal{f}$ 1985;110:535-41.

28 National Heart Foundation of Australia. Information Paper 19. Canberra: National Heart Foundation, 1984.

29 Leeder SR, Gibberd RW, Dobson AJ, Lloyd DM. Declining mortality rates from ischaemic heart disease in Australia. Aust NZ J Med 1984;14:388-94. 30 Smith DP, Slater C. The pattern of ischaemic heart disease 1931-1980. Stat Med 1985;4:397.

(Accepled l August 1989)

\section{Correction}

Influence of maternal diet during lactation and use of formula feeds on development of atopic eczema in high risk infants

Two editorial errors occurred in this paper by Ranjit Kumar Chandra and others (22 July, pp 228-30). The conclusions in the abstract should read, "In families with a history of atopic disease [not eczema, as stated] mothers who breast feed should avoid common allergenic foods during lactation." The first sentence in the subjects and methods section should read, "In cases in which either of the baby's parents had a history [not a family history] of atopic disease mothers were asked whether they planned to breast feed exclusively."

\section{Case-control study of infections with Salmonella} enteritidis phage type 4 in England

Two authors' errors occurred in this paper by Dr John M Cowden and others (23 September, pp 771-3). In the last sentence of the first paragraph on $\mathrm{p} 772$ "the first three" was omitted, and later in the sentence a percentage of $0.02 \%$ was given. The sentence should read, "Of 137 patients, $26(19 \%)$ ate at least one of the first three products specified in the table compared with only four $(2 \%)$ of the 196 controls." 